\title{
Cystic Degeneration of Fibroid following Mifepristone
}

\author{
${ }^{1}$ Nutan Jain, ${ }^{2}$ Mohsina Hakim
}

\begin{abstract}
Uterine leiomyomas are common uterine tumors and often altered by degenerative changes, which can cause difficulty and confusion in their clinical diagnosis. Several agents exist for the medical management of uterine fibroids through symptom control, reduction in fibroid volume, and reduction in menstrual blood loss. In our patient, Tab. mifepristone $25 \mathrm{mg}$ was used for 9 months. In follow-up, size of fibroid tripled over 9 months. Patient started developing pressure symptoms. Surgery was difficult to perform because of cystic degeneration. Further long-term study is needed to exactly understand the long-term effect of these medicines.
\end{abstract}

Keywords: Cystic degeneration, Leiomyoma, Mifepristone.

How to cite this article: Jain N, Hakim M. Cystic Degeneration of Fibroid following Mifepristone. Int J Gynecol Endsc 2017;1(1):46-49.

\section{Source of support: Nil}

Conflict of interest: None

\section{BACKGROUND}

Uterine leiomyomas are common uterine tumors, and typical cases of leiomyoma are easily diagnosed by imaging study. However, uterine leiomyomas are often altered by degenerative changes, which can cause difficulty and confusion in their clinical diagnosis. Women who wish to conceive are nowadays more likely to present with uterine fibroids, mainly because of the delay in childbearing in our society. Contemporary medical management of uterine fibroids exploits the estrogen and progesterone responsiveness of uterine fibroids; however, no pharmacological agent is curative of fibroids. As a result, medical therapy is essentially a treatment option for the control of symptoms. Several agents exist for the management of uterine fibroids through symptom control, reduction in fibroid volume, and reduction in menstrual blood loss. The most commonly used agents have been gonadotropin-releasing hormone $(\mathrm{GnRH})$ analogs. Newer, novel therapies including aromatase

\footnotetext{
${ }^{1}$ Director, ${ }^{2}$ Clinical Research Fellow

1,2Department of Gynaecology, Vardhman Trauma \& Laparoscopy Centre, Muzaffarnagar, Uttar Pradesh, India

Corresponding Author: Nutan Jain, Director, Department of Gynaecology and Obstetrics, Vardhman Trauma \& Infertility Centre, Muzaffarnagar, Uttar Pradesh, India, Phone: +9101312623084, e-mail: jainnutan@gmail.com
}

inhibitors, mifepristone, selective estrogen receptor modulators, and selective progesterone receptor modulators have shown promise in symptom improvement and fibroid regression without the hypoestrogenic symptoms associated with GnRH analogs. ${ }^{1}$ Myomectomy is still the "gold standard" in fibroid treatment for fertilitywishing patients. In experienced hands, hysteroscopic myomectomy is minimally invasive, safe, and effective. Abdominal and laparoscopic myomectomy might be challenging, but potential risks could be reduced by new strategies and techniques.

\section{CASE REPORT}

Recently, we had a case of huge fibroid uterus with cystic degeneration. A 33-year-old premenopausal nulliparous lady married since 1 year, came to our outpatient department with sonography findings of big fibroid uterus. It was first noticed by her husband around 10 months earlier as a lump in her lower abdomen. Sonography was done. It was diagnosed to have fibroid uterus about $6 \mathrm{~cm}$ in size. She consulted a local gynecologist. She was prescribed Tab. mifepristone $25 \mathrm{mg}$ daily for 9 months. She had regular follow-up with sonography. She left her medication 1 month ago. During her medication, she had amenorrhea for 6 months. Now, she presented to us with complains of heavy bleeding per vaginum, constipation, and increased frequency of urination for 1 month. She also noticed increasing size of mass per abdomen. There was no history of severe pain abdomen. Her recent sonography showed a well-defined fibroid of $22 \mathrm{~cm}$ size arising from anterior wall of uterus with irregular internal cystic changes suggestive of cystic degeneration. On clinical examination, her vital signs were unremarkable. Per abdomen examination showed a mass occupying whole lower abdomen reaching up to 28 weeks size uterus (Fig. 1). It was firm in consistency, smooth surface, and nontender. Her blood and urine investigations were normal. After complete workup, we planned to do laparoscopic myomectomy. On insertion of laparoscope, uterus was uniformly enlarged about 26 to 28 weeks in size, reaching above aortic bifurcation. Adnexa were normal (Fig. 2). No ascitic fluid was noted. We usually inject Pitressin before myomectomy. When we put the laparoscopic needle to inject vasopressin, about $500 \mathrm{~mL}$ of yellow colors clear fluid came out through myoma. As soon as incision was done, soft cystic yellow jelly-like pulpaceous myoma 


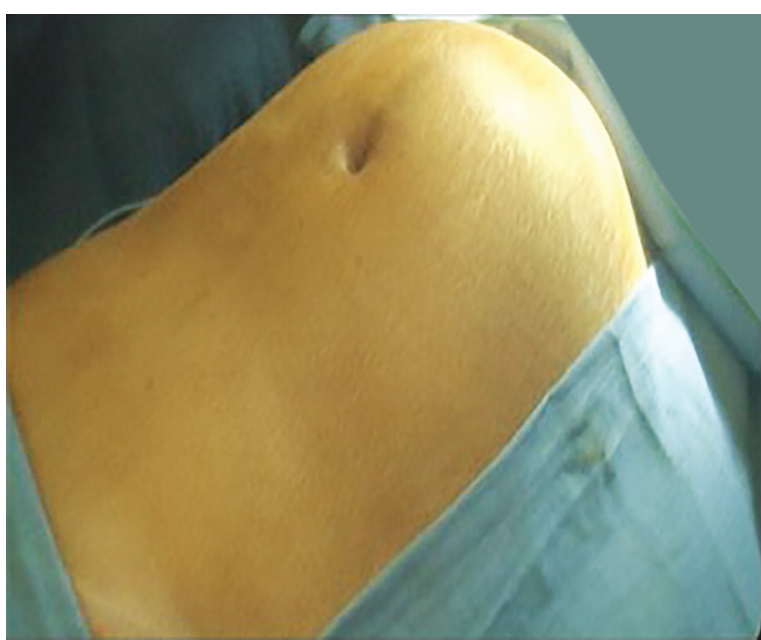

Fig. 1: Fibroid uterus per abdomen about 28 weeks size

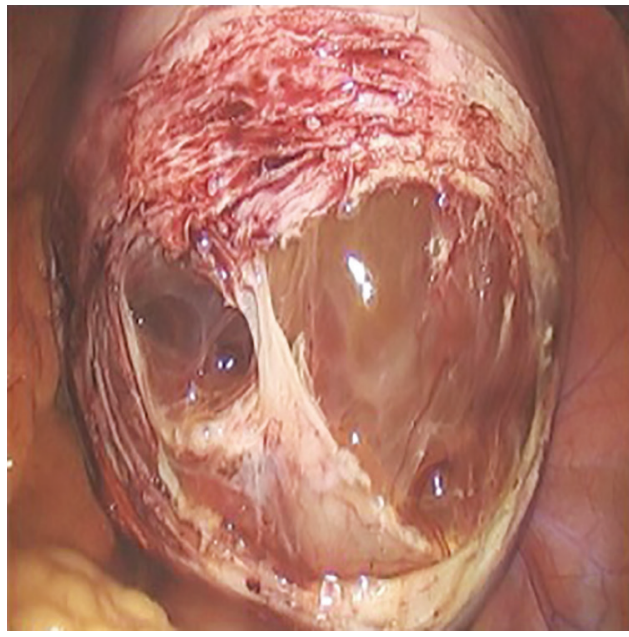

Fig. 3: Cystic degeneration of fibroid

popped out. There was complete obliteration of myoma plane. It was very difficult to handle the pulpaceous myoma and to ensure that all was removed as the proper plane cleavage was totally lost (Figs 3 and 4). It was a really tedious task to handle and to remove in totality. Myoma bed was sutured in layers (Fig. 5). Specimen sent for histopathology showed fibroid uterus with cystic degeneration.

\section{DISCUSSION}

Myomas are remarkably common. Fine serial sectioning of uteri from 100 consecutive women who underwent hysterectomy found myomas in $77 \%$, including some as small as $2 \mathrm{~mm} .^{2}$ A random sampling of women aged 35 to 49 who were screened by self-report, medical record review, and sonography found that by age 35 the incidence of myomas was $60 \%$ among African-American women; the incidence increased to over $80 \%$ by age 50 . Caucasian women have an incidence of $40 \%$ by age 35 , and almost $70 \%$ by age $50 .{ }^{3}$

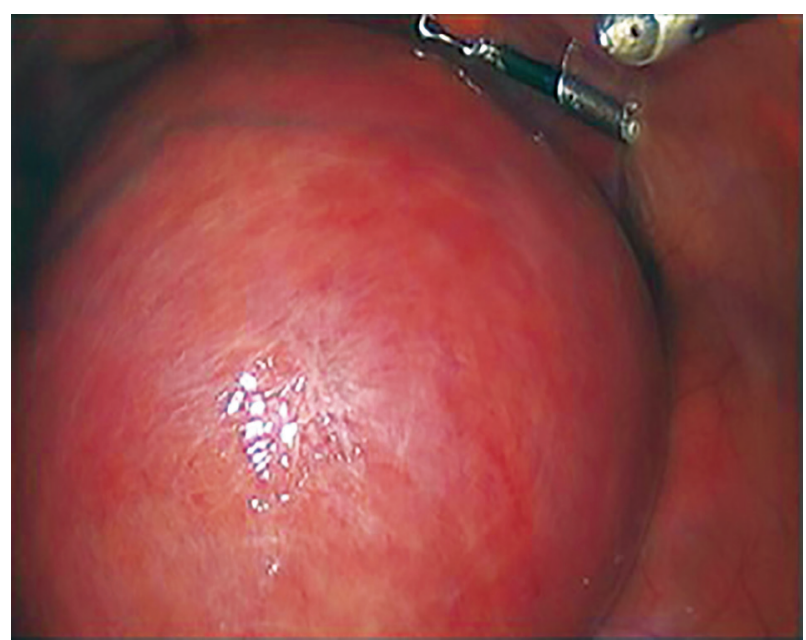

Fig. 2: Intraoperative size of myoma

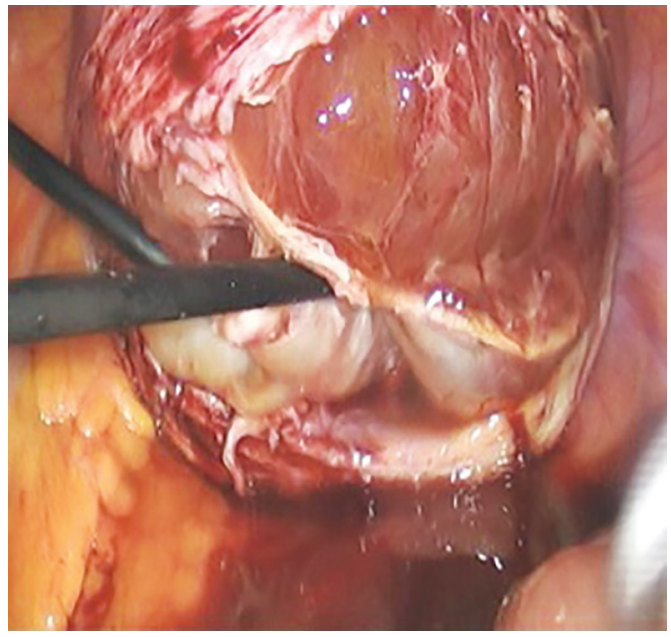

Fig. 4: Pulpacious material from myoma

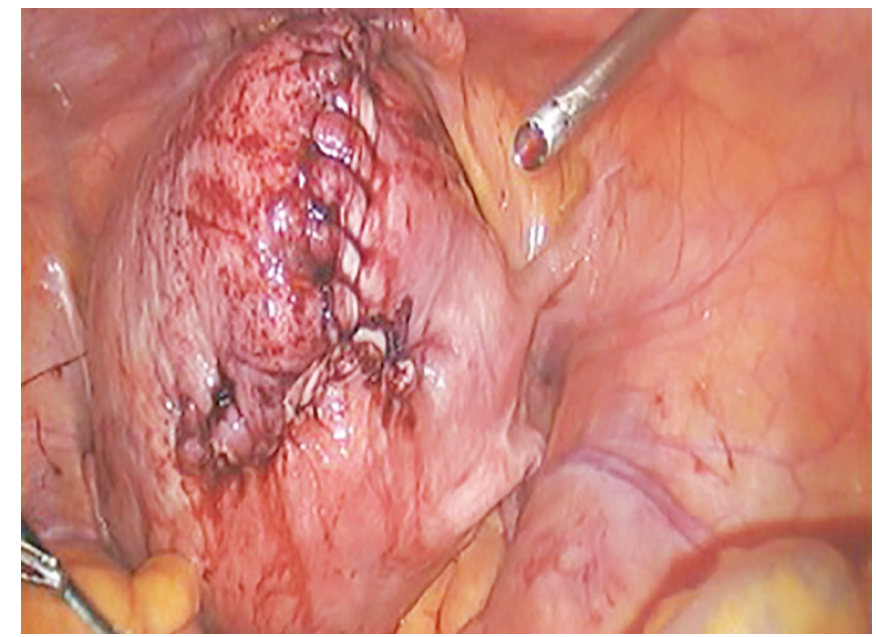

Fig. 5: Uterus sutured

Myomas are benign, monoclonal tumors of the smooth muscle cells of the myometrium. They are composed of large amounts of extracellular matrix containing collagen, fibronectin, and proteoglycan. Collagen type I and type III are abundant, but the collagen fibrils are 
formed abnormally and are in disarray, much like the collagen found in keloid formation., ${ }^{4,5}$

Degeneration of uterine leiomyomas occurs when they enlarge and outgrow their blood supply. This is seen more commonly in pregnant women or women who are taking oral contraceptive pills. ${ }^{6}$ Degenerative or secondary changes are detectable in approximately $65 \%$ of uterine leiomyomas: Hyaline degeneration $(63 \%)$, myxoid changes (19\%), calcification ( $8 \%$ ), cystic changes $(4 \%)$, fatty metamorphosis $(3 \%)$, and red degeneration (3\%). ${ }^{7}$ Hydropic degeneration characterized by the intratumoral accumulation of edematous fluid is also known as degeneration of uterine leiomyomas. ${ }^{7}$

The diagnosis of degenerating uterine leiomyoma in nonpregnant women is often difficult. The inflammation in the case of degeneration can cause abdominal tenderness, localized rebound tenderness on palpation, elevation of temperature, and leukocytosis. ${ }^{8}$ On rare occasions, a degenerating leiomyoma can rupture and result in intraabdominal bleeding. ${ }^{9}$ Preoperative diagnosis of degenerative leiomyomas is often difficult and commonly misinterpreted as complex adnexal cysts of ovarian origin. ${ }^{10}$ However, in our case, none of the above typical presentation was there. So authors assume that mifepristone may be the reason of cystic degeneration of fibroid in this case.

Mifepristone (RU 486) is a progesterone receptor modulator with primarily antagonistic properties. It binds strongly to endometrial progesterone receptors, minimally to estrogen receptors, and upregulates androgen receptors. ${ }^{11}$ In a placebo-controlled trial, low-dose mifepristone (RU 486) has been shown to decrease myoma size as well as symptoms. ${ }^{12}$ Reduction in size with mifepristone might be due to the direct effect in reducing number of progesterone receptors. Besides, because of ovarian acyclicity seen with mifepristone, hormonal milieu similar to early follicular phase may also inhibit steroid-dependent growth of myoma. Increase in androg en receptors also contributes to antiproliferative effects. ${ }^{13}$ Mifepristone also delays or inhibits ovulation, which may produce amenorrhea. Direct suppressive effects on endometrial vasculature as well as on reducing stromal vascular endothelial growth factor has also been suggested for reducing menstrual blood loss. ${ }^{13,14}$ Mifepristone, as a treatment option for myoma, was first reported by Murphy et $\mathrm{al}^{15}$. Further studies evaluated mifepristone in doses varying from 2.5 to $50 \mathrm{mg}$ / day given for 3 to 6 months, and doses as high as $50 \mathrm{mg}$ and as low as $5 \mathrm{mg}$ were found effective in ameliorating myoma-related symptoms like dysmenorrhea, menorrhagia, and pelvic pressure, and reducing myoma volume by 26 to $57 \%$ and inducing amenorrhea in 41 to $100 \% .{ }^{16-23}$

\section{CONCLUSION}

Though various pharmacological agents are available that claim to decrease the myomas in size and symptoms, various literature supports $25 \mathrm{mg}$ mifepristone taken over 6 months reduces myoma size by 26 to $57 \%$. In clinical practice, it is not so. Long-term effects of these medicines are not available. So medical management should be used judiciously for symptomatic relief of fibroid in selected group of patients. Large size fibroid should be managed with surgical approach.

\section{REFERENCES}

1. Carranza-Mamane B, Havelock J, Hemmings R; Reproductive Endocrinology and Infertility Committee, Cheung A, Sierra S, Carranza-Mamane B, Case A, Dwyer C, Graham J, et al. The management of uterine fibroids in women with otherwise unexplained infertility. J Obstet Gynaecol Can 2015 Mar;37(3):277-288.

2. Cramer SF, Patel A. The frequency of uterine leiomyomas. Am J Clin Pathol 1990 Oct;94(4):435-438.

3. Baird DD, Dunson DB, Hill MC, Cousins D, Schectman JM. High cumulative incidence of uterine leiomyoma in black and white women: ultrasound evidence. Am J Obstet Gynecol 2003 Jan;188(1):100-107.

4. Stewart EA, Friedman AJ, Peck K, Nowak RA. Relative overexpression of collagen type I and collagen type III messenger ribonucleic acids by uterine leiomyomas during the proliferative phase of the menstrual cycle. J Clin Endocrinol Metab 1994 Sep;79(3):900-906.

5. Kawaguchi K, Fujii S, Konishi I, Nanbu Y, Nonogaki H, Mori T. Mitotic activity in uterine leiomyomas during the menstrual cycle. Am J Obstet Gynecol 1989 Mar;160(3):637-641.

6. Rein MS, Barbieri RL, Friedman AJ. Progesterone: a critical role in the pathogenesis of uterine myomas. Am J Obstet Gynecol 1995 Jan;172(1 Pt 1):14-18.

7. Rosai, J. Rosai and Ackerman's surgical pathology. 10th ed. Vol. 2. London: Mosby; 2011. p. 15.

8. Tan YL, Naidu A. Rare postpartum ruptured degenerated fibroid: a case report. J Obstet Gynaecol Res 2014 May;40(5): 1423-1425.

9. Takai H, Tani H, Matsushita H. Rupture of a degenerated uterine fibroid as a cause of acute abdomen: a case report. J Reprod Med 2013 Jan-Feb;58(1-2):72-74.

10. Kaushik C, Prasad A, Singh Y, Baruah BP. Case series: cystic degeneration in uterine leiomyomas. Indian J Radiol Imaging 2008 Feb;18(1):69-72.

11. Spitz IM. Clinical utility of progesterone receptor modulators and their effect on the endometrium. Curr Opin Obstet Gynecol 2009 Aug;21(4):318-324.

12. Engman M, Granberg S, Williams AR, Meng CX, Lalitkumar PG, Gemzell-Danielsson K. Mifepristone for treatment of uterine leiomyoma. A prospective randomized placebo controlled trial. Hum Reprod 2009 Aug;24(8):1870-1879.

13. Narvekar N, Critchley HO, Cheng L, Baird DT. Mifepristoneinduced amenorrhoea is associated with an increase in microvessel density and glucocorticoid receptor and a decrease in stromal vascular endothelial growth factor. Hum Reprod 2006 Sep;21(9):2312-2318.

14. Spitz IM. Mifepristone: where do we come from and where are we going? Clinical development over a quarter of a century. Contraception 2010 Nov;82(5):442-452. 
15. Murphy AA, Morales AJ, Kettel LM, Yen SS. Regression of uterine leiomyomata to the antiprogesterone RU486: doseresponse effect. Fertil Steril 1995 Jul;64(1):187-190.

16. Yang Y, Zheng S, Li K. Treatment of uterine leiomyoma by two different doses of mifepristone. Zhonghua Fu Chan Ke Za Zhi 1996 Oct;31(10):624-626.

17. Eisinger SH, Meldrum S, Fiscella K, le Roux HD, Guzick DS. Low-dose mifepristone for uterine leiomyomata. Obstet Gynecol 2003 Feb;101(2):243-250.

18. Eisinger SH, Bonfiglio T, Fiscella K, Meldrum S, Guzick DS. Twelve-month safety and efficacy of low-dose mifepristone for uterine myomas. J Minim Invasive Gynecol 2005 MayJun;12(3):227-233.

19. Fiscella K, Eisinger SH, Meldrum S, Feng C, Fisher SG, Guzick DS. Effect of mifepristone for symptomatic leiomyomata on quality of life and uterine size: a randomized controlled trial. Obstet Gynecol 2006 Dec;108(6):1381-1387.
20. Carbonell Esteve JL, Acosta R, Heredia B, Pérez Y, Castañeda MC, Hernández AV. Mifepristone for the treatment of uterine leiomyomas: a randomized controlled trial. Obstet Gynecol 2008 Nov;112(5):1029-1036.

21. Bagaria M, Suneja A, Vaid NB, Guleria K, Mishra K. Low-dose mifepristone in treatment of uterine leiomyoma: a randomised double-blind placebo-controlled clinical trial. Aust N Z J Obstet Gynaecol 2009 Feb;49(1):77-83.

22. Esteve JL, Acosta R, Pérez Y, Campos R, Hernández AV, Texidó CS. Treatment of uterine myoma with 5 or $10 \mathrm{mg}$ mifepristone daily during 6 months, post-treatment evolution over 12 months: double-blind randomised clinical trial. Eur J Obstet Gynecol Reprod Biol 2012 Apr;161(2):202-208.

23. Eisinger SH, Fiscella J, Bonfiglio T, Meldrum S, Fiscella K. Open-label study of ultra low-dose mifepristone for the treatment of uterine leiomyomata. Eur J Obstet Gynecol Reprod Biol 2009 Oct;146(2):215-218. 